\title{
High doses of Uvaria chamae root extract impair sperm motility and viability
}

\author{
Godwin Adakole Ujah ${ }^{1, *}$, Ileri-Oluwa Busayo Emmanuel ${ }^{2}$, Bassey Emmanuel Emeng ${ }^{1}$, and \\ Patience Favour KaLU ${ }^{1}$
}

${ }^{1}$ Department of Physiology, University of Calabar, Calabar, Nigeria

${ }^{2}$ Biomedicinal Research Centre, Forestry Research Institute of Nigeria, Ibadan, Nigeria

*Corresponding author: gasukole@yahoo.com

Published: December 25, 2021

Received: January 14, 2021

Accepted: September 15, 2021

Published on-line: December 10, 2021

\begin{abstract}
Uvaria chamae is a tropical medicinal plant with documented antimicrobial and antimalarial activities. Agents with these activities are known to impair fertility. This study investigated the antifertility effects of ethanolic extract of $U$. chamae on male albino Wistar rats. Two different oral doses; 56.6 $\mathrm{mg} / \mathrm{kg}$ body weight and $113.2 \mathrm{mg} / \mathrm{kg}$ body weight of the extracts were administered to low dose and high dose group, respectively. A third group served as control and received $2 \mathrm{~mL}$ of distilled water. There were five animals in each group. Administration lasted six weeks after which animals were sacrificed and samples collected. Results showed that sperm count, sperm morphology and semen $\mathrm{pH}$ were not affected $(P>0.05)$ by the extract. Sperm motility $(55.65 \%)$ and viability $(64.38 \%)$ were however decreased $(\mathrm{P}<0.05)$ by high doses of the extract. Histopathology of testicular tissues also showed no difference across the groups. U. chamae thus impair fertility in vivo especially at high doses.
\end{abstract}

Key words: Uvaria chamae; fertility; sperm motility; viability

http://dx.doi.org/10.5937/leksir2141058U

\section{INTRODUCTION}

The use of herbs for medicine is a traditional practice as old as man (Ujah, 2017). It remains a common practice today especially in developing countries where there is a significant reliance on herbal medicine as primary health care (Ekpe et al., 1990). The main reasons for this include cost, availability and efficacy of these herbs. Extracts from leaves, seeds, barks, stems and roots of herbs are usually administered for the management and treatment of many diseases (Ogbulie et al., 2004).

Uvaria chamae is a medicinal plant belonging to the family Annonaceae. It is common to the tropical rain forest of West Africa (Irvin, 1961). Extracts of $\mathcal{U}$. chamae have been scientifically reported to have anti-inflammatory (Okwu and Iroabuchi, 2009), anti-anaemic (Okon et al., 2013), anti-snake venom (Okon et al., 2013), antibiotic (Ogbulie et al., 2007), anti-ulcer (Chilaka et al., 2010) and antimalarial (Okokon et al., 2006) effects.

Antibiotic and antimalarial agents have been reported to impair fertility. Quinine and chloroquine have been shown to have anti-fertility effects (Adeeko and Dada, 1998). Stem bark extracts of Quassia amara and Alstonia boonei have been documented to impair fertility. Both plants are known to possess antimalarial activity (Raji and Bolarinwa, 1997; Raji et al., 2005). Buchholzia coriacea seed extracts have been shown to have anti- malarial property (Okoli et al., 2010). They were also reported to impair male fertility (Obembe et al., 2012).

The antibiotic and antimalarial properties of $U$. chamae have been established. Given that many agents with these properties impair fertility, whether or not $U$. chamae also impair fertility is not known. This study thus seeks to establish that This study also seeks to establish the dose at which $U$. chamae may impair fertility.

\section{MATERIALS AND METHODS}

\subsection{Extract preparation}

Mature roots of $U$. chamae were obtained from the botanical garden of University of Calabar, Cross River State, Nigeria. They were authenticated at the herbarium of Botany Department, University of Calabar and deposited under the voucher number 327. The roots were rinsed with tap water and cut into pieces of smaller shapes and shed-dried. The shed-dried root was blended into powder. The amount of $250 \mathrm{~g}$ of the blended extract was weighed and percolated with $10 \mathrm{~L}$ of $95 \%$ ethanol. This was done for 14 days at room temperature. The extract was then filtered and using rotary evaporator was concentrated to dryness in vacuum. The extract was then stored in a freezer until used. 

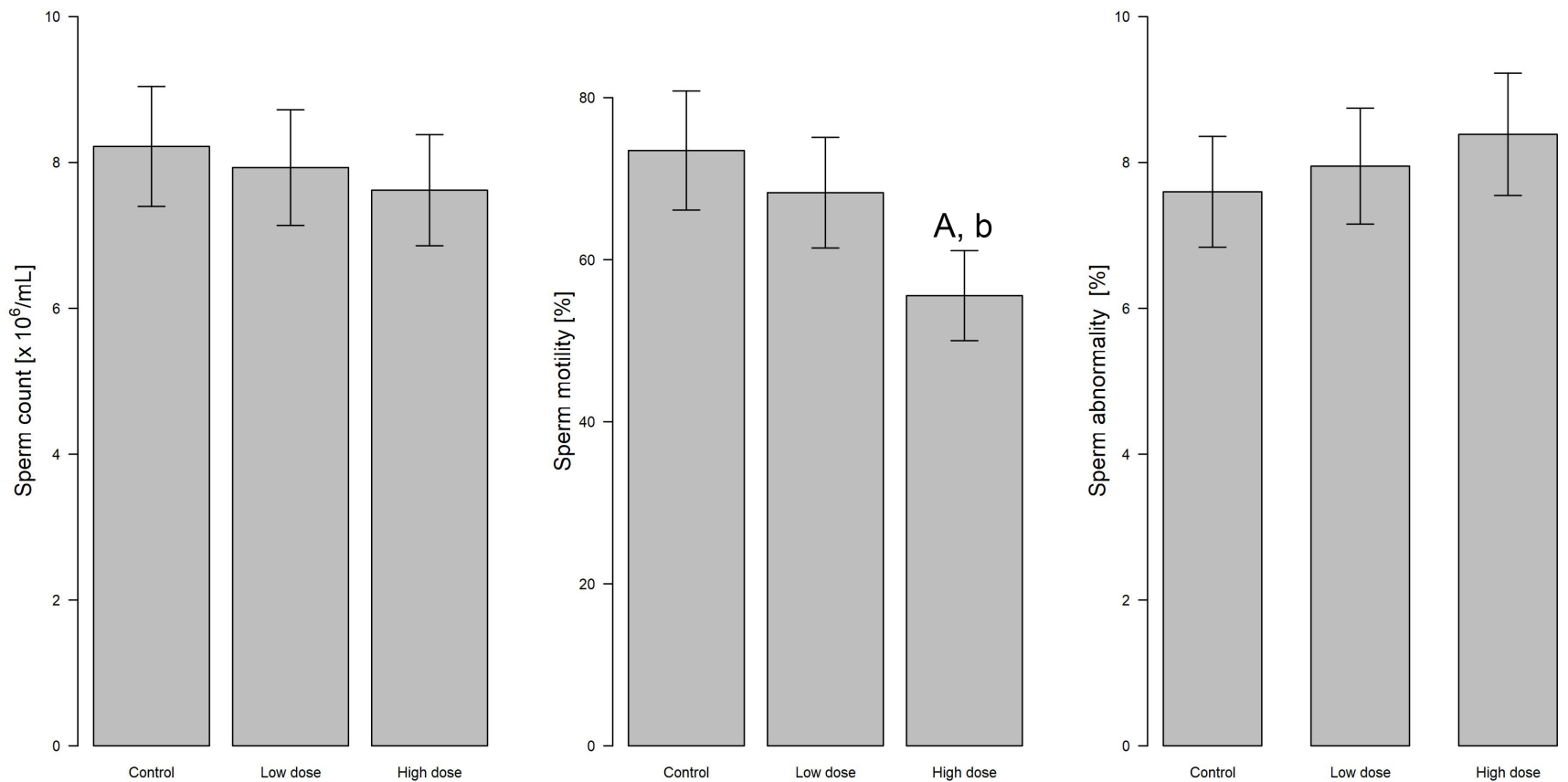

Fig. 1. Comparison of sperm count, mobility and abnormality in the different experimental groups; A - statistical difference at level $\mathrm{P}<0.001$ vs. Control; b - statistical difference at level $\mathrm{P}<0.01$ vs. Low dose

\subsection{Determination of median lethal dose $\left(\operatorname{LD}_{50}\right)$}

The median lethal dose $\left(\mathrm{LD}_{50}\right)$ of $U$. chamae was determined using the method described by Lorke (1983). Thirty Swiss albino mice weighing between 20-25 g were intraperitoneally administered with staircase doses of 100, 200, 400, 800 and $1600 \mathrm{mg} / \mathrm{kg}$ of the $U$. chamae extract. The animals were then observed for possible manifestation of physical signs of toxicity, and the number of deaths within $24 \mathrm{~h}$ period was recorded. The median lethal dose was calculated mathematically as the geometric mean of the maximum dose producing $0 \%$ mortality and the minimum dose that produced $100 \%$ mortality by equation

$$
L D_{50}=\sqrt{D_{0} \times D_{100}},
$$

where $\mathrm{LD}_{50}$ is median lethal dose, $\mathrm{D}_{0}$ is maximum dose that produced $0 \%$ mortality and $\mathrm{D}_{100}$ is minimum dose that produced $100 \%$ mortality.

\subsection{Experimental animals and design}

Adult male albino Wistar rats (150 -200 g) were allowed to acclimatize for two weeks in the Animal House of the Department of Physiology at the University of Calabar under standard conditions. They were allowed free access to normal rat feed and clean water for the period of acclimatization. All experiments were carried out with strict compliance to "The Principle of Laboratory Animal Care" (NIH Publication No. 85-23) and approved institutional protocols on animal handling.

Two doses (selected based on the $\mathrm{LD}_{50}$ ) of the extract 56.6 $\mathrm{mg} / \mathrm{kg}$ body weight and $113 \mathrm{mg} / \mathrm{kg}$ body weight were orally administered to animals in low and high dose groups respectively for six weeks. A third group served as control and received distilled water as vehicle for same duration. All groups consisted of five animals each. At the end of six weeks, rats were sacrificed under chloroform anesthesia. Blood samples were collected by cardiac puncture for testosterone assay and the testes and epididymis were excised for semen and sperm analyses.

\subsection{Sperm count}

Epididymal sperm samples were obtained by macerating the caudal epidermis in normal saline in the ratio 1:10 (weight/volume). This was then pipetted to release the sperm cells and filtered using an $80 \mu \mathrm{m}$ stainless mesh. Sperm count was obtained by cytometry using improved Neubauer cytometer (Hausser scientific, Pennsylvania, USA) and was expressed in million/mL of the sperm suspension (Ekaluo et al., 2008).

\subsection{Sperm mobility}

Two drops of sperm suspension were placed on a slide and then covered with a cover slip. Progressively motile sperm cells were counted and divided by the total number of sperm cells and expressed in percentage. Counting was done under $\times 40$ magnification (Ekaluo et al., 2008).

\subsection{Sperm viability}

Sperm viability was determined by eosin-nigrosin staining technique (Bjorndahl, 2003). Equal volumes of sperm suspension and eosin-nigrosin stain were mixed and air-dried smears prepared on glass slides. The slides were then examined for percentage viability. Viable sperm cells appeared unstained while dead sperm cells absorbed the stain and appeared pinkish. Percentage viability was calculated based on the number of viable sperm cells out of the total number of sperm cells (dead and alive) observed.

\subsection{Sperm morphology}

Air-dried smears of sperm suspension mixed with $1 \%$ eosin Y solution (10:1) were made on glass slides for sperm abnormality test. The slides were observed for percentage sperm abnormalities in every 200 spermatozoa observed. The percentage of sperm abnormality was calculated according to previously described methods by Wyrobek and Bruce (1978). 


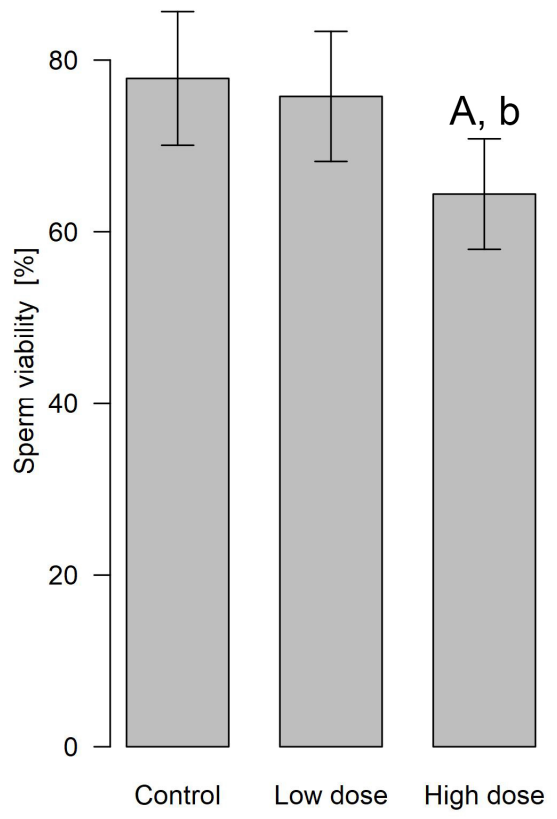

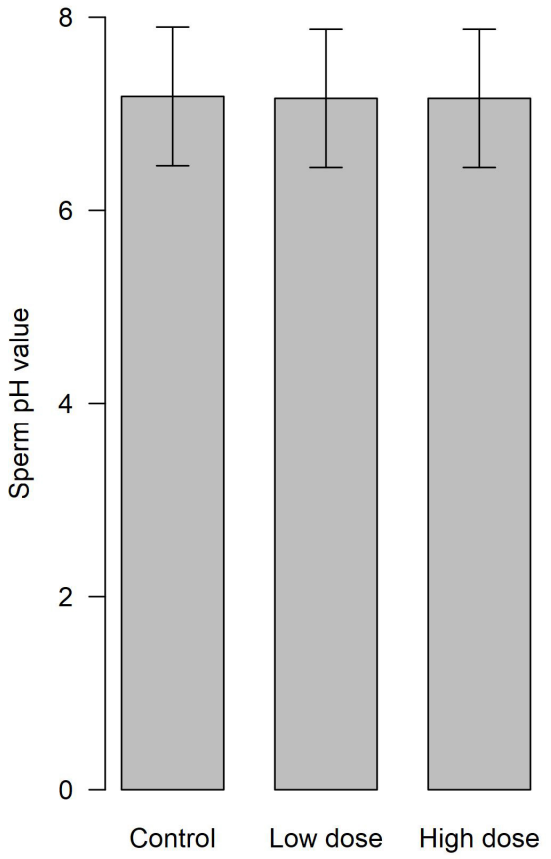

Fig. 2. Comparison of sperm viability and $\mathrm{pH}$ value in the different experimental groups; $\mathrm{A}$ - statistical difference at level $\mathrm{P}<0.001 \mathrm{vs}$. Control; $\mathrm{b}$ - statistical difference at level $\mathrm{P}<0.01$ vs. Low dose
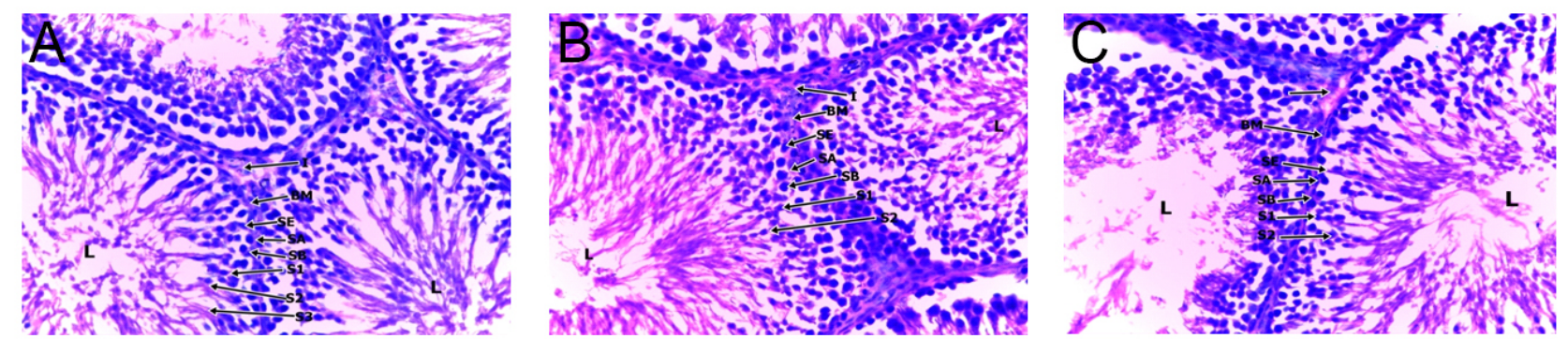

Fig. 3. Sections through the testes of rats. Spermatogenesis appears to be normal in all groups ( $\times 400$ magnification); A - control, B - low dose, C - high dose; BM - basement membrane, SA - spermatogonia A, SB - spermatogonia B, S1 - primary spermatocytes, S2 - secondary spermatocytes, S3 - spermatid, L - lumen, SE - sertoli cell

\subsection{Semen $\mathrm{pH}$}

Immediately after dissection, a puncture was made in the epididymis with a sterile pin. The semen $\mathrm{pH}$ was then determined using a hand held $\mathrm{pH}$ meter (New Jersey, USA).

\subsection{Testicular histopathology}

Histological examination of the testis was done using haematoxylin and eosin ( $\mathrm{H}$ and $\mathrm{E})$ technique. Briefly, the right testis of the animals were harvested and fixed in Bouin's fluid, dehydrated, then embedded in blocks of paraffin. Tissue blocks were sectioned, stained with $\mathrm{H}$ and $\mathrm{E}$ and viewed using a light microscope (DP70, Olympus, Tokyo, Japan) (Nna et al., 2017).

\subsection{Statistical analysis}

Results were expressed as mean \pm SEM. Statistical analysis was done using computer software SPSS version 20.0. One way analysis of variance (ANOVA) followed by post hoc multiple comparisons test was used to compare mean values among groups. $\mathrm{P}<0.05$ was the criterion for statistical significance.

\section{RESULTS}

The median lethal dose $\left(\mathrm{LD}_{50}\right)$ was $169.8 \mathrm{mg} / \mathrm{kg}$ body weight. There was no significant difference in the sperm count in both the low dose and high dose extract-treated groups when compared with the control (Figure 1A). No significant change was observed in sperm motility following treatment with low dose of $U$. chamae extracts when compared with the control. There was however a significant decrease $(P<0.05)$ in sperm motility of the high dose extract-treated group when compared with both control and low dose extract-treated groups (Figure 1B). There were no significant changes in the sperm abnormality (sperm morphology) of the control and extracttreated groups (Figure 1C). While there was no significant difference in the sperm viability between the control and the low dose extract-treated groups, there was however a significant decrease $(\mathrm{P}<0.05)$ in the sperm viability of the high dose extract-treated group when compared to both control and low dose extract-treated groups (Figure 2A). Semen $\mathrm{pH}$ showed no significant change between control and extract-treated groups (Figure 2B). 
Histopathological examination of testes showed that the control group (Figure 3A) had closely packed seminiferous tubules with intact basement containing proliferating germ cells at various level of maturation. The cells have prominent deeply stained nuclei and are 3 to 5 cells thick. The sertoli cells are up to 12 per tubules with basally located nuclei closed to the basement membrane. The cells include the spermatogonia $\mathrm{A}$ and $\mathrm{B}$, primary spermatocytes located closed to the basement membrane and the secondary spermatocytes, spermatids and spermatozoa closed to the lumen. The intertubular interstitium is sparse and contain 3 to 5 leydig cells. The low dose extract-treated group (Figure $3 \mathrm{~B}$ ) showed closely packed seminiferous tubules with intact basement containing proliferating germ cells at various level of maturation. The cells are 3 to 5 cells layer thick with regular nuclei outline and fine chromatin pattern. The supporting sertoli cells are prominent an up to 12 per tubules. Their lumina are filled with numerous spermatozoa.

The high dose extract-treated group (Figure 3C) showed closely packed seminiferous tubules with intact basement containing proliferating germ cells at various level of maturation. The cells are 3 to 5 cells layer thick with regular nuclei outline and fine chromatin pattern. The supporting sertoli cells are prominent up to 12 per tubules. Their lumina are filled with spermatozoa and some of the tubules consists of spermatogonia and numerous spermatids.

\section{DISCUSSION}

The extracts of $U$. chamae have been reported to possess several beneficial effects. This has formed the rationale for the widespread use of this plant extracts in traditional medicine. This study has however revealed that extracts of $U$. chamae interferes with male fertility in vivo as was seen by a decrease in sperm motility and viability. The fertilizing capacity of sperm cells is related to their motility (Rhemrev et al., 2001). Sperm cells are produced in the testes, but acquire maturity and motility capability in the epididymis (Yoshida et al., 2008). The decrease in sperm motility and viability with $U$. chamae treatment suggests the extracts of the plant may have a toxic effect on the epididymis especially at high doses. In a previous study, we showed that $U$. chamae contained phytochemicals like alkaloids and tannins among others (Enin et al., 2021). Alkaloids have been shown to decrease motility (Trifunac and Bernstein, 1982). In that study, an antimalarial agent (chloroquine) was found to impair motility just like in this current study. Tannins also have been shown to decrease motility (Zhou et al., 2012). The presence of these phytochemicals in $U$. chamae extract may have been responsible for the decrease in sperm motility and viability in this study. This becomes a more serious concern as oftentimes in traditional medicine the extracts are taken at unknown doses. A lower dose (56.6 $\mathrm{mg} / \mathrm{kg}$ ) however had no such motility-decreasing effect as results show. Testicular spermatogenesis seemed to be unaffected as there were no changes in the sperm count and morphology with extract administration. This was corroborated by histopathology of testes where normal spermatogenesis was seen in all groups. The mechanism by which high dose of $U$. chamae impairs sperm motility and viability is not known, hence there is need for a follow-up investigation to ascertain this.

\section{CONCLUSION}

High doses of Uvaria chamae impair male fertility by decreasing sperm motility and viability.

\section{FUNDING}

This research did not receive any specific grant from funding agencies in the public, commercial, or not-for-profit sectors.

\section{REFERENCES}

Adeeko, A. O. and Dada, O. A. (1998). Chloroquine reduces fertilizing capacity of epididyma sperm in rats, African Journal of Medicine and Medical Sciences 27(1-2): 63-64.

Bjorndahl, L. (2003). Evaluation of the one-step eosin-nigrosin staining technique for human sperm vitality assessment, Human Reproduction 18(4): 813-816.

Chilaka, K. C., Unekwe, P. C., Chilaka, J. U. and Nweke, I. N. (2010). Studies on the anti-ulcer properties of ethanolic leaf extracts of Uvaria chamae, Tropical Journal of Medical Research 14(2). Number: 2.

Ekaluo, U. B., Udokpoh, A. E., Ikpeme, E. and Peter, E. (2008). Effect of chloroquine treatments on sperm count and weight of testes in male rats, Global Journal of Pure and Applied Sciences 14(2): 175-177.

Ekpe, E., Ebana, R. and Madunagu, B. E. (1990). Anti-microbial activity of four medicinal plants on pathogenic bacteria and phytopathogenic fungi, West African Journal of Biological and Applied Chemistry .

Enin, G. N., Shaibu, S. E., Ujah, G. A., Ibu, R. O. and Inangha, P. G. (2021). Phytochemical and nutritive composition of Uvaria chamae P. Beauv. leaves, stem bark and root bark, ChemSearch Journal 12(1): 9-14.

Irvin, F. R. (1961). Woody plants of Ghana with special reference to their uses, Oxford University Press, London.

Lorke, D. (1983). A new approach to practical acute toxicity testing, Archives of Toxicology 54: 275-287.

Nna, V. U., Ujah, G. A., Mohamed, M., Etim, K. B., Igba, B. O., Augustine, E. R. and Osim, E. E. (2017). Cadmium chloride-induced testicular toxicity in male wistar rats; prophylactic effect of quercetin, and assessment of testicular recovery following cadmium chloride withdrawal, Biomedicine \& Pharmacotherapy 94: 109-123.

Obembe, O. O., Onasanwo, S. A. and Raji, Y. (2012). Preliminary study on the effects of Buchholzia coriacea seed extract on male reproductive parameters in rats, Nigerian Journal of Physiological Sciences: Official Publication of the Physiological Society of Nigeria 27(2): 165-169.

Ogbulie, J. N., Ogueke, C. C. and Nwanebu, F. C. (2007). Antibacterial properties of Uvaria chamae, Congronema latifolium, Garcinia kola, Vemonia amygdalina and Aframomium melegueta, African Journal of Biotechnology 6(13). Number: 13.

Ogbulie, J., Ogueke, C. and Okorondu, S. (2004). Antibacterial properties of $A$. corditola, M. flurum, U. chaeme, B. pinnatum, C. albidem and acilata on some hospital isolates., Nigerian Journal of Microbiology 18(1-2): 249-255.

Okokon, J. E., Ita, B. N. and Udokpoh, A. E. (2006). The in-vivo antimalarial activities of Uvaria chamae and Hippocratea africana, Annals of Tropical Medicine \& Parasitology 100(7): 585-590.

Okoli, B. J., Okere, O. S. and Adeyemo, S. O. (2010). The antipalasmodial activity of Buchholzia coriacea, Journal of Medical and Applied Biosciences 2: 21-29.

Okon, J. E., Udosen, I. R. and Mbong, E. O. (2013). Phytochemical screening and effect of ethanolic root extract of Uvaria chamae on haematological parameters on albino rats in Akwa Ibom state, Nigeria, Merit Research Journals 1(2): 16-20.

Okwu, D. E. and Iroabuchi, F. (2009). Phytochemical composition and biological activities of Uvaria chamae and Clerodendoron splendens, E-Journal of Chemistry 6(2): 553-560.

Raji, Y. and Bolarinwa, A. F. (1997). Antifertility activity of Quassia amara in male rats - in vivo study, Life Sciences 61(11): 1067-1074.

Raji, Y., Salman, T. M. and Akinsomisoye, O. S. (2005). Reproductive functions in male rats treated with methanolic extract of Alstonia boonei stem bark, African Journal of Biomedical Research 8: 7.

Rhemrev, J. P., Lens, J. W., McDonnell, J., Schoemaker, J. and Vermeiden, J. P. (2001). The postwash total progressively motile sperm cell count is a reliable predictor of total fertilization failure during in vitro fertilization treatment, Fertility and Sterility 76(5): 884-891.

Trifunac, N. P. and Bernstein, G. S. (1982). Inhibition of the metabolism and motility of human spermatozoa by various alkaloids, Contraception 25(1): 69-87.

Ujah, G. A. (2017). Effect of aqueous leaf extract of Mangifera indica on differential white blood cell count, International Journal of Innovative Research and Advanced Studies 3(10): 123-125. 
Wyrobek, A. J. and Bruce, W. R. (1978). The induction of sperm shape abnormalities in mice and humans, in A. Hollaender and J. F. de Serres (eds), Chemical mutagens. Principles and methods for their detection., Vol. 5, Plenum Press, New York and London, pp. 257-285.

Yoshida, M., Kawano, N. and Yoshida, K. (2008). Control of sperm motility and fertility: Diverse factors and common mechanisms, Cellular and Molecular Life Sciences 65(21): 3446-3457.

Zhou, B., Qiu, Z., Liu, G., Liu, C. and Zhang, J. (2012). Spermicidal and antigonococcal effects of tannins from pomegranate rind, Journal of Medicinal Plants Research 6(7): 1334-1339. 